\title{
Optimising Daylighting Performance in Tropical Courtyard and Atrium Buildings for Occupants' Wellbeing
}

\author{
Muhammad Syukri Talip', Mariam Felani Shaari1', Sabarinah Sh Ahmad¹, Ricardo B Sanchez² \\ ${ }^{1}$ Centre of Studies for Architecture, Faculty of Architecture, Planning and Surveying, \\ Universiti Teknologi MARA, Selangor, Malaysia. \\ 2 National Autonomous University of Mexico, Mexico City, Mexico.
}

syukritalip@gmail.com, mariamfelani@uitm.edu.my, sabar643@uitm.edu.my, sanchezrick99@comunidad.unam.mx

Tel: +60196690045

\begin{abstract}
Daylighting has attracted increasing attention from researchers as an energy-efficient and sustainable building design technique. This research investigates the daylighting of atrium and courtyard building by comparing the performance of various Window to Wall Ratios (WWR) appropriate to Malaysia's tropical climate. The most acceptable option for daylight performance was to specify a moderate WWR value of $30 \%$ with shading devices. The results of The Radiance Daylighting Simulations confirmed the daylight performance by a comparison of calculated data and modelling. The findings show the combinations of daylighting parameters that work for courtyard and atrium buildings for the occupants' wellbeing.
\end{abstract}

Keywords: Daylighting Performance, Courtyard, Atrium, Tropical, Radiance Simulations

eISSN: 2398-4287@ 2021. The Authors. Published for AMER ABRA CE-Bs by e-International Publishing House, Ltd., UK. This is an open access article under the CC BYNC-ND license (http://creativecommons.org/licenses/by-nc-nd/4.0). Peer-review under responsibility of AMER (Association of Malaysian Environment-Behaviour Researchers), ABRA (Association of Behavioural Researchers on Asians/Africans/Arabians) and CE-Bs (Centre for Environment-Behaviour Studies), Faculty of Architecture, Planning \& Surveying, Universiti Teknologi MARA, Malaysia.

DOI: https://doi.org/10.21834/ebpj.v6i16.2710

\subsection{Introduction}

Daylight is an environmental benefit an atrium and courtyard can harness for a building. Natural light limits artificial light usage from the atrium and courtyard. It also promotes psychological and ergonomic factors to enhance the interior. Daylight of adjacent rooms is determined by vertical levels of daylight at the walls of the well and room properties (reflections for scale and surface). The geometries of the well and floor reflections are very important. Atrium and courtyard elements directly impact on the vertical levels of the building. Much work on daylight in atria has been based on illumination in the atrium and courtyard well (Du \& Sharples, 2011). But studies of daylight levels are less common in adjacent rooms and well walls.

The atrium and courtyard architecture is dynamic and provides relations between multiple criteria that must be grasped and considered in the final design. According to Hussain \& Oosthuizen (2012), atrium and courtyard architecture maximizes the natural environment. Many forms can be designed, but atrium and courtyard configurations will still serve as a solution for sustainable climate objectives. Building features can be enclosed in whole or in part of traditional atrium and courtyard architecture. The atrium and courtyard layout determine many of the atrium and courtyard characteristics. The structure and geometry of the atrium, courtyard, and neighbouring inhabited building elements are subject to the expected functions. The basic configuration of the atrium and courtyard is

eISSN: 2398-4287@ 2021. The Authors. Published for AMER ABRA cE-Bs by e-International Publishing House, Ltd., UK. This is an open access article under the CC BYNC-ND license (http://creativecommons.org/licenses/by-nc-nd/4.0). Peer-review under responsibility of AMER (Association of Malaysian Environment-Behaviour Researchers), ABRA (Association of Behavioural Researchers on Asians/Africans/Arabians) and CE-Bs (Centre for Environment-Behaviour Studies), Faculty of Architecture, Planning \& Surveying, Universiti Teknologi MARA, Malaysia.

DOI: https://doi.org/10.21834/ebpj.v6i16.2710 
both simple and complex. Designer selected issues include a feature of personal taste (among other issues), safety concerns, potential uses of both the atrium and courtyard, neighbouring spaces, and the environment effect that the atrium and courtyard desires.

\subsection{Issues and Problem Statement}

In many studies in commercial buildings, daylight was identified as a problem, especially in the case of plaza or shopping malls that maximum daylight to limit electricity usage for artificial lighting. Two points remain a challenge. Firstly, spaces for different functions were designed. Secondly, special lighting requirements by JKR lighting guidelines are needed. Moreover, problems of daylighting also include glare in tropical climate conditions.

\subsection{Aim and Objectives}

The present research aims to compare the space opening configuration between atrium and courtyard to maximize daylight efficiency, as the enhancement of daylight in built areas affects occupant's mood as well as light distribution.

Objectives are:

i) To optimize the daylight redirection system

ii) To enhance quality and distribution of daylight

iii) To study how building spaces influence thermal comfort

\subsection{Research Scope}

There are two configuration parameters studies:

i) Opening - Atrium, Courtyard, different window-to-wall ratios (WWR)

ii) Spacing - area distribution of daylight

\subsection{Literature Review}

Daylighting requires the use of windows, atrium, courtyard, and reflective surfaces. Given the impact of daylighting on visual as well as thermal comfort, the design of buildings to maximise daylighting and improve energy consumption is paramount. Moreover, the design of building spaces can impact the distribution of daylighting in various buildings and impact human function (Shaari et al., 2020). Therefore, building designs that influence the distribution of daylighting impact human behaviour. Also, daylight levels in adjacent rooms are determined by vertical daylight levels in the walls of the well (scale and surface reflections) (Du \& Sharples, 2011).

The design of the opening is not sufficient and additional light redirection elements are needed to further boost daylight efficiency and restrict illumination as discussed above. Mansfield (2018) showed how development is applied through building architecture. He highlights the importance of daylight conception criteria in galleries and strongly suggests that light control elements be added. However, all these experiments were conducted with light redirecting elements on a window. Other studies were based on daylight efficiency simulations (Hussain \& Oosthuizen, 2012; Marzouk, Eissa, \& ElSharkawy, 2020). Also, According to the daytime structure and artificial adaptive control features, the capacity to provide adequate illumination was emphasised (Caicedo \& Pandharipande, 2015).

The tropical climate has complex sky conditions. The hourly Nebulosityu NI index data shows that in Subang, Malaysia, $85.6 \%$ of times in the celestial landscape are mainly intermediate (2.2\% intermediate, $67.0 \%$ intermediate blue, $17.3 \%$ intermediate blue, $15.0 \%$ cloudy, $0,0 \%$ blue) (Zain-Ahmed et al., 2002). In contrast, throughout the year the sky using the $\mathrm{NI}$ method is $100 \%$ intermediate. Irradiance data and suggested luminous efficiency constants were applied for global illumination in tropical regions. The global lighting at midday in March exceeds $80 \mathrm{k}$ lux and in December approaches $60 \mathrm{k}$ lux less (Zain-Ahmed et al., 2002). Previous studies also showed that world lighting could exceed $100 \mathrm{k}$ lux (Zain-Ahmed et al., 2002). Therefore, the estimated value of $20 \mathrm{k}$ lux of global light is available for the daylight factor (DF) analysis in cloudy skies in tropical climates (Lim, Ahmad, \& Ossen, 2013). In daytime building, designers and architects involve regulated lighting conditions to ensure maximum visual convenience. The specific standards for illumination level are only taken into account in Malaysia. This code of illumination practices refers to light quality as described in Malaysian Standard 1525:2014 to provide sufficient indoor lighting in the 300-400 lux range.

\subsection{Methodology}

\subsection{Data Collection}

The Integrated Environmental Solution (IES-VE) was used as a method to model the daylight efficiency of different architectural atria and courtyards. IES-VE employs a daylight simulation Radiance-based engine using the calculate method of ray-tracing. This software measures the distribution of the emissions and helps to reflect, distributing and refracting surfaces. Therefore the results of the IESRadiance simulation were validated using 3D models. The 3D model replicates light behaviour in buildings. Thus, the performance and precision of the model were also demonstrated as representing daytime performance under actual conditions in the atmosphere.

\subsection{Building Geometry}

The model building consists of a three-level office building on each floor that consists of a thermal environment. The objective was to assess daylighting. In this comparison case, the analysis presumes that the building is entirely illuminated by the outside windows. Maximum room size, $L$, can thus be determined by the equation (1). Note that the value $L$ will double if the windows are located on the 
opposite side:

$$
\frac{L}{W}+\frac{L}{H w}<\frac{2}{1-R b}
$$

If $\mathrm{W}$ is the height in the room, $\mathrm{Hw}$ is the height over the floor of the window, and $\mathrm{Rb}$ is the normal surface reflex in the back (out of the glass). Recent research calculated that the building diameter was $35 \mathrm{~m}$, the window head height (Hw) was $2.8 \mathrm{~m}$ and the reflection of $\mathrm{Rb}$ 0.5. It is the average depth of space for efficient daylighting for one hand as shown in Equation (1). This benefit is almost doubled as windows are supplied on opposite directions. The analysis then proposed a plane depth equivalent to that of $15 \mathrm{~m}$.

The tropical climates need to reduce the glazing to a lower indoor temperature. This research analyzed three WWR values from 10 $\%$ to $30 \%$ with $10 \%$ increments to assess its impact on daylighting efficiency. Windows were given as equivalent rectangular openings in the reference building under examination and considered to be equal in each elevation. For comparative purposes, the courtyard and atrium cases were combined with the field corresponding to the WWR analyzed for the reference cases (Table 1). Two situations, shading devices were studied in the investigated cases. South façades typically feature horizontal shading schemes. Consequently, horizontal shades of both facades, taking into consideration a depth of $0.6 \mathrm{~m}$, are required to suit the daylight and lighting criteria (Lau, Salleh, Lim, \& Sulaiman, 2016).

\subsection{Modelling Case}

The analysis took four configurations into account. Each of them displays a structure of $35 \times 35 \mathrm{~m}$ which was modelled before and after shading equipment was used. Each of the three configurations examined Table 1 indicates a plan area.

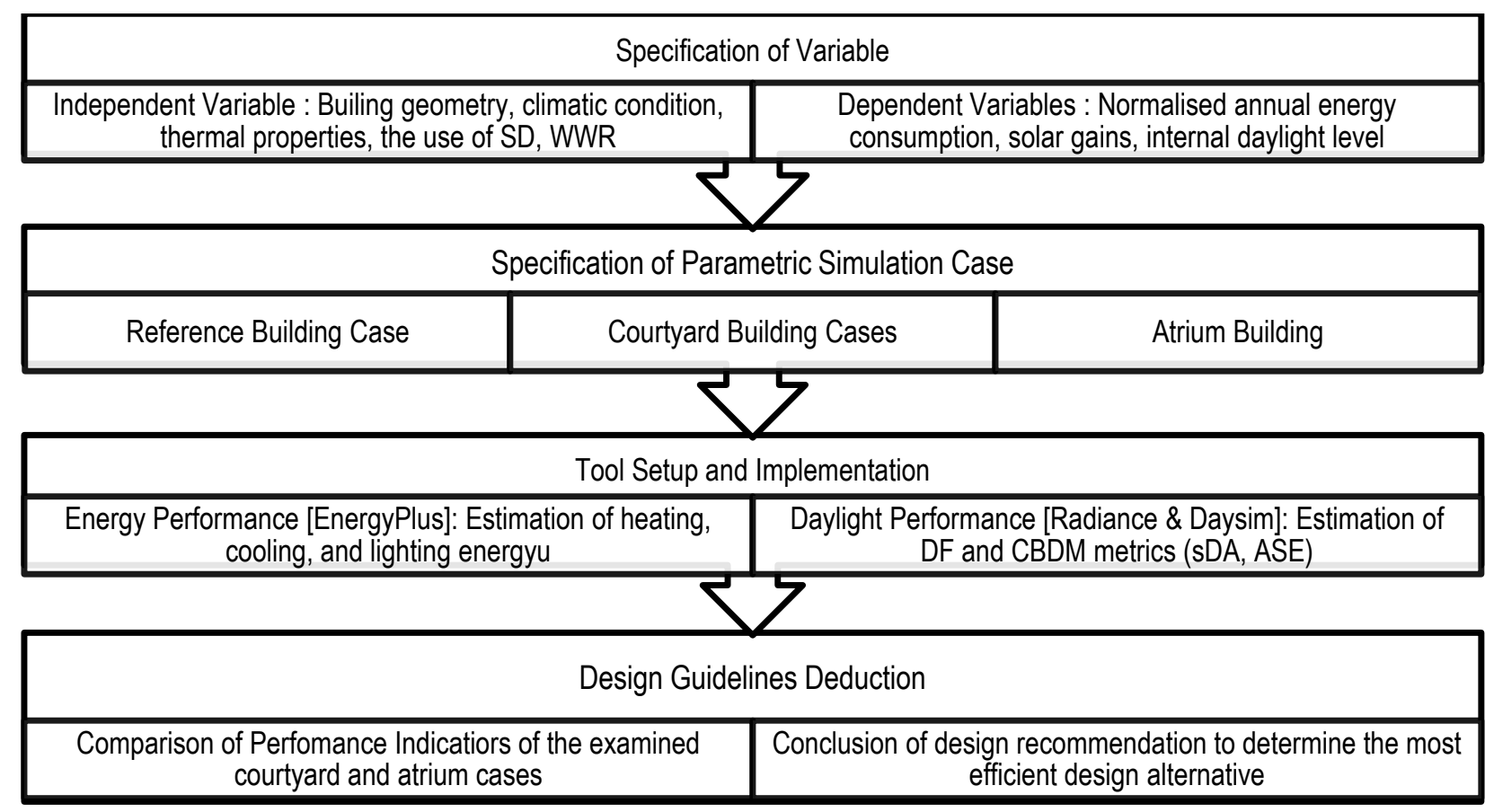

Fig. 1. Parametric research flow diagram (Source: Author) 
Table 1. Prepare region of the cases investigated.

\begin{tabular}{|c|c|c|c|}
\hline & Reference cases & Courtyard case & Atrium Case \\
\hline Dimensions of Building (m) & $35 \times 35$ & $35 \times 35$ & $35 \times 35$ \\
\hline Courtyard and Atrium dimension (m) & -- & $15 \times 15$ & $15 \times 15$ \\
\hline floor area of the building $\left(\mathrm{m}^{2}\right)$ & $\begin{array}{c}1300 \\
\text { (Ground floor) } \\
1000 \\
\left.\text { (1st floor }-3^{\text {rd }} \text { floor }\right)\end{array}$ & 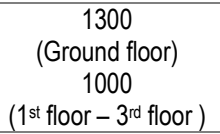 & $\begin{array}{c}1300 \\
\text { (Ground floor) } \\
1000 \\
\left.\text { (1st floor }-3^{\text {rd }} \text { floor }\right)\end{array}$ \\
\hline No. of Windows & 288 & 288 & 288 \\
\hline $\begin{array}{l}\text { External façade window area } \\
\text { Window Area (WWR=10) }\end{array}$ & 103.7 & 103.7 & 103.7 \\
\hline Dimension of Windows & $0.6 \mathrm{~m} \times 0.6 \mathrm{~m}$ & $0.6 \mathrm{~m} \times 0.6 \mathrm{~m}$ & $0.6 \mathrm{~m} \times 0.6 \mathrm{~m}$ \\
\hline Dimension additional opening & -- & $4 \mathrm{~m} \times 4 \mathrm{~m}$ & $4 \mathrm{~m} \times 4 \mathrm{~m}$ \\
\hline Additional courtyard or atrium window area & -- & 16 & 16 \\
\hline Total $\left(m^{2}\right)$ & 103.7 & 111.7 & 117.7 \\
\hline $\begin{array}{l}\text { External façade window area } \\
\text { Window Area (WWR=20) }\end{array}$ & 207.4 & 207.4 & 207.4 \\
\hline Dimension of Windows & $1.2 \mathrm{~m} \times 0.6 \mathrm{~m}$ & $1.2 \mathrm{~m} \times 0.6 \mathrm{~m}$ & $1.2 \mathrm{~m} \times 0.6 \mathrm{~m}$ \\
\hline Dimension additional opening & -- & $9.5 \mathrm{~m} \times 9.5 \mathrm{~m}$ & $9.5 \mathrm{~m} \times 9.5 \mathrm{~m}$ \\
\hline Additional courtyard or atrium window area & -- & 90.25 & 90.25 \\
\hline Total $\left(m^{2}\right)$ & 207.4 & 297.7 & 297.7 \\
\hline $\begin{array}{l}\text { External façade window area } \\
\text { Window Area }(W W R=30)\end{array}$ & 414.7 & 414.7 & 414.7 \\
\hline Dimension of Windows & $1.2 \mathrm{~m} \times 1.2 \mathrm{~m}$ & $1.2 \mathrm{~m} \times 1.2 \mathrm{~m}$ & $1.2 \mathrm{~m} \times 1.2 \mathrm{~m}$ \\
\hline Dimension additional opening & -- & & \\
\hline Additional courtyard or atrium window area & -- & 225 & 225 \\
\hline Total $\left(m^{2}\right)$ & 414.7 & 639.7 & 639.7 \\
\hline
\end{tabular}

(Source: Author)

The three cases are illustrated in Table 1. The findings were standardised by the building occupied floor area to ensure equal contrast between the cases studied, as shown in Table 2.

Table 2. Building configuration.

Reference Configuration Courtyard Configuration
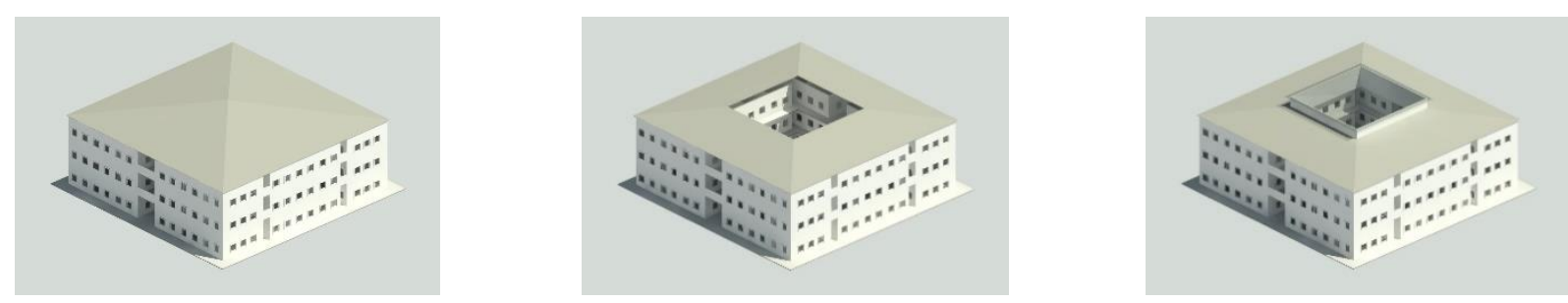

b) With shading devices

(Source: Author)

- $\quad$ Configuration of the reference: No courtyard or atrium. Daylight shines through the glass of the house located on exterior lifts.

- The courtyard setting: in this case there is a square courtyard in the central area (15X15 m). The court was built using Design Builder's 'Draw Vacuum Perimeter' tool to generate an additional courtyard length. Daylight penetrates the building both externally and internally through windows.

- The atrium setting: this case is fitted with an atrium of $15 \times 15 \mathrm{~m}$ in the center. The atrium was built using Design Builder's "draw door" device, which resulted in an inner atrium length. Besides the top of the lateral atrium, sunshine penetrates through the windows situated on the exterior elevations. 


\subsection{Simulation Framework}

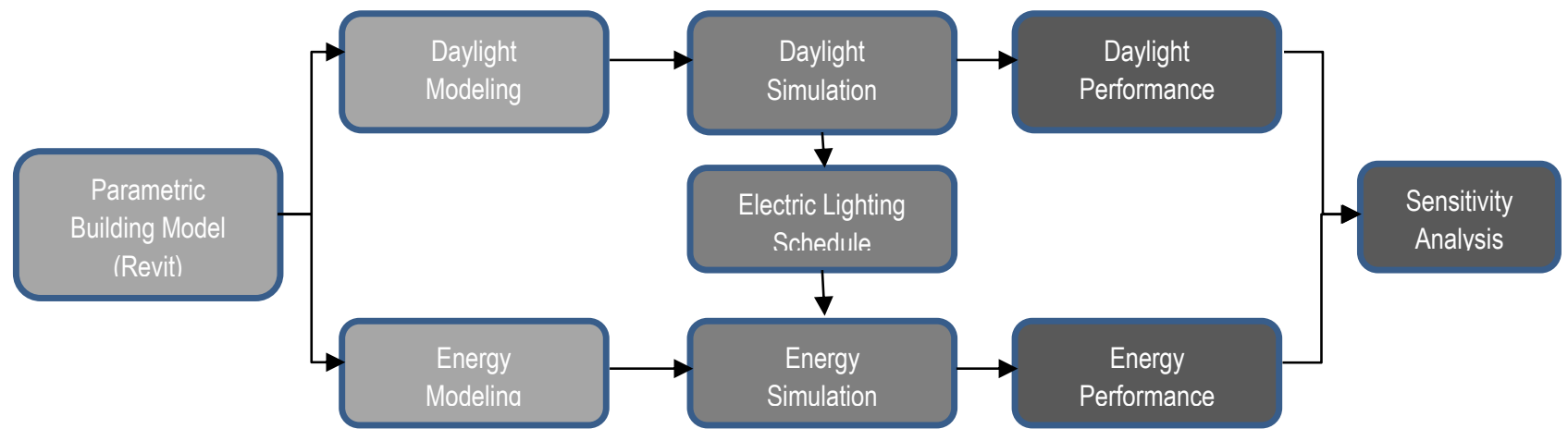

Fig. 2. Simulation framework. (Source: Author)

The research framework is shown in Figure 2. The investigation starts with the creation of 3 design variables in the parametric construction geometry. Insight plug-ins are used for daylight modelling and radiance simulation is performed. To examine the heating, cooling and lighting charges simultaneously an integrated daylighting is designed. A simulation of daylighting is measured for every hour per day.

\subsection{Numerical Analysis Tool Setting}

In this analysis, 3D concept building models were used for the measurement of daylight of the examined radiance events. Revit2Radiance as daylight simulation Software were used by DesignBuilder (Gourlis \& Kovacic, 2017) These methods provide one approach, widely used in daylight evaluation. The conventional method of measuring lighting levels on some given working plane of the building based on DF or illumination average. In this regard, detailed multizone estimation of illumination rates based on gloomy CIE sky conditions was rendered by the simulation engine (Bellia, Fragliasso, \& Stefanizzi, 2017). The daylight engine Daysim has been used to generate a variety of daylight metrics (Ayoub, 2019):

- Spatial daylight autonomy (SDA): The percentages of the work plane which has at least $30 \%$ of annually occupied hours with a predefined lighting level. For example, occupied for at least $30 \%$ of the hours each year, sDA500/30\% corresponds to a proportion of the work planes that earn a minimum of 500 lux.

- Annual Sunshine Exposure (ASE): Typically 250 hours of direct sunshine within a certain level (1000 lx) of the working aircraft. Usually, this calculation alongside SDA is used to take into account the chance of lighting.

- Effective lighting of the day: It is used to measure the average light intensity in the workplanes within the predefined range of 100 to 2000 lux (UDI100-2000) of useful daylight illumination.

In this analysis, the first two metrics were taken as data on the daylight availability. For daylight modelling, the following settings have been implemented:

- Location: Shah Alam, Selangor, Malaysia

- $\quad$ Latitude $=101.5185^{\circ}$, longitude. $=3.0733^{\circ}$

- Height of workplane $=9$ meter

- $\quad$ CIE overcast day (for estimating the DF) pattern.

- Indoor lighting standard comparison $=500$ lux in commercial buildings and offices buildings

- The threshold for ASE illuminance: 1000 lux

- Area width simulation: $35 \mathrm{~m} \times 35 \mathrm{~m}$

\subsection{Findings}

\subsection{Daylighting Performance Analysis}

Table 3 shows the internal distribution of luminance using varying DF levels in the central workplane of the courtyard and atrium case under consideration for this study. As we can see, the daylight distribution pattern was symmetrical in both building configurations. It also shows the daylight rates on the operating plane of the examined court and atrium before and after the use of shading systems that take specific WWR values into consideration. From initial observations, we can see that varying WWR values result in different light. 
Table 3. The daylight rates on the operating plane.

\begin{tabular}{|l|l|l|l|l|}
\hline \multicolumn{2}{|c|}{ Before the Use of SD } & \multicolumn{2}{l|}{ After the Use of SD } \\
\hline Courtyard & Atrium & Courtyard & \\
\hline & & & & \\
\hline
\end{tabular}

(Source: Author)

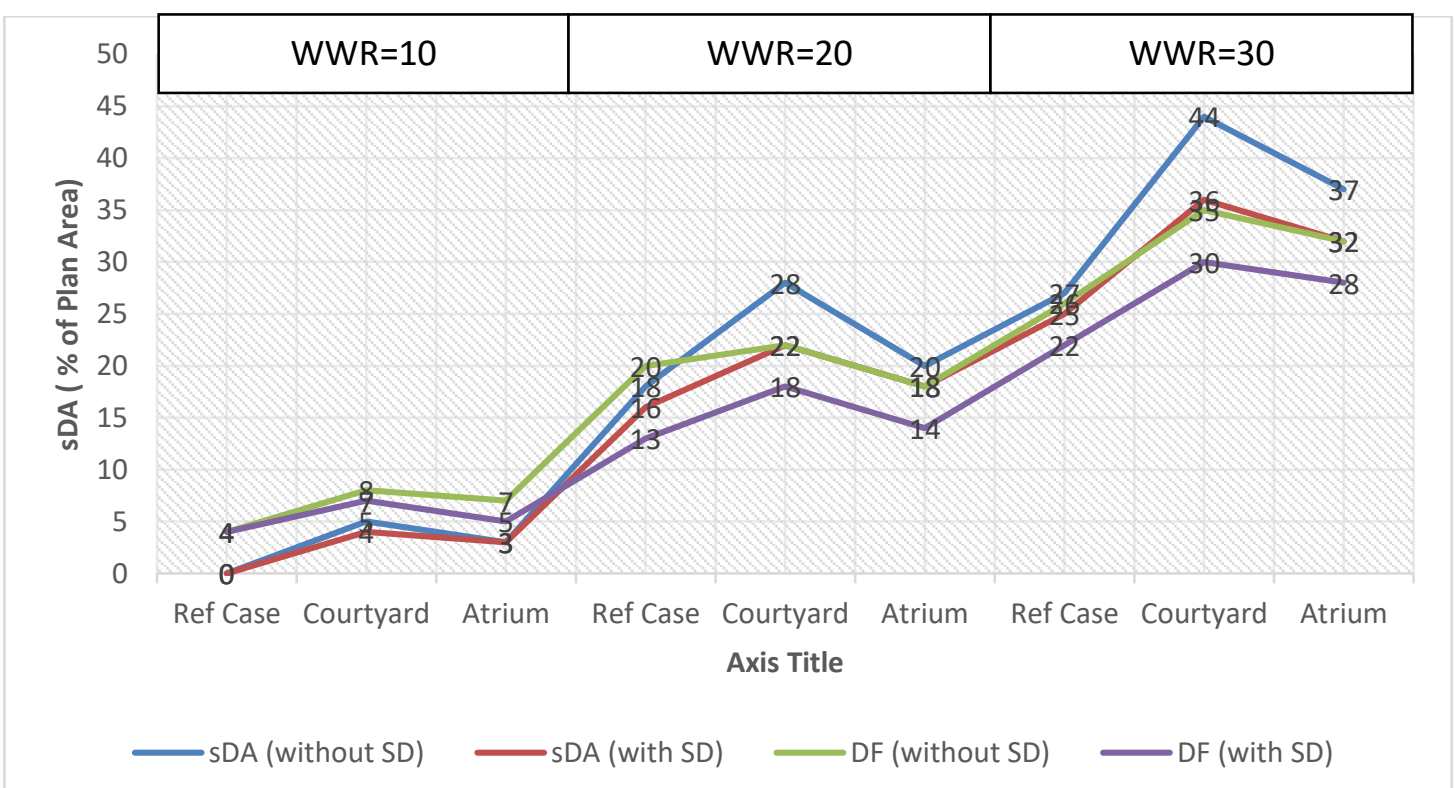

Fig. 3. Average DF and SDA values before and after shading devices that consider different WWR values in the examined situations. (Source: Author) 


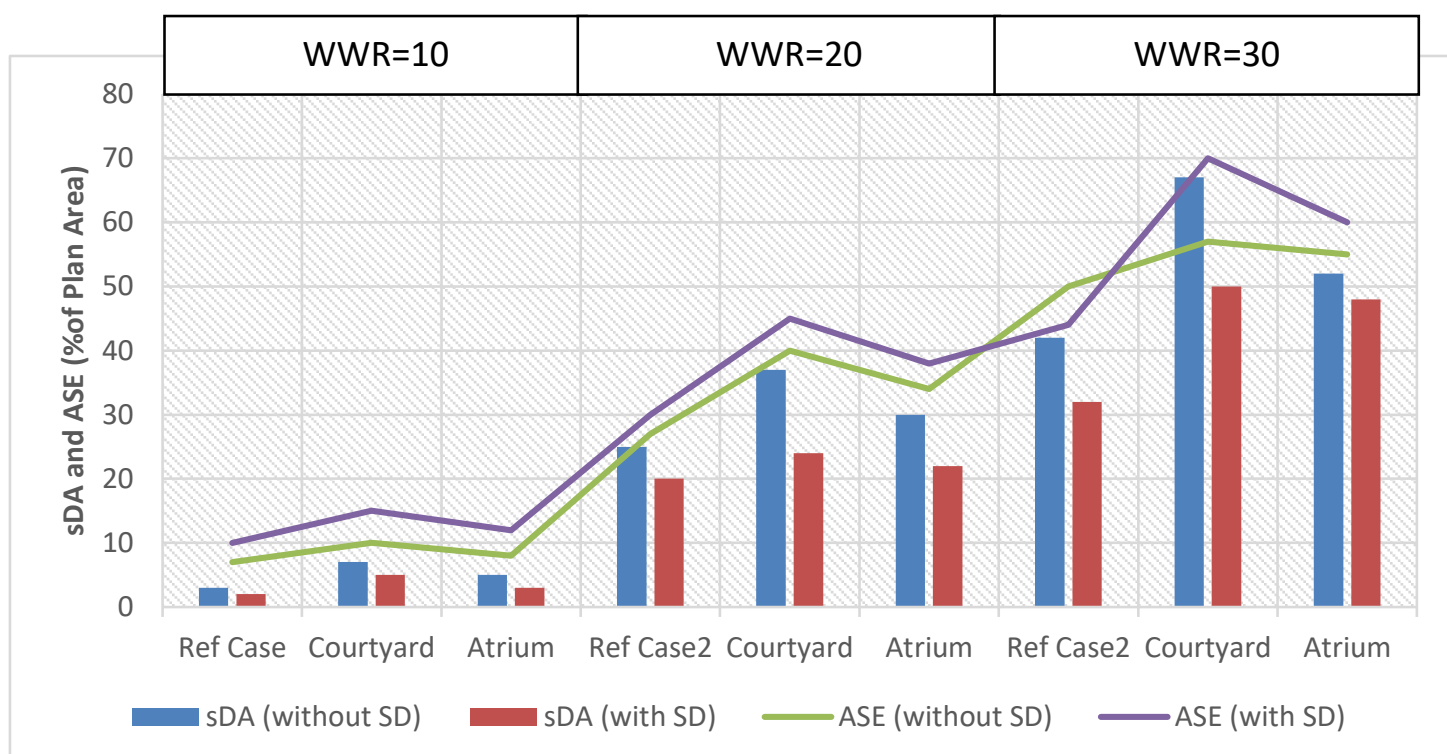

Fig. 4. Average SDA and ASE values before and after usage of shading devices with different WWR values in the cases studied. (Source: Author)

Figures 3 and 4 demonstrate the quality of daylight in the investigated cases before and after the use of shading. In the first approach only SDA was observed, whereas, in the second approach, two metrics were measured: SDA and ASE. Since the DF test was considered true, the combined use of SDA and ASE values has the primary benefit of demonstrating the availability and distribution of daylight. Moreover, the amalgamation of these figures could also assess the possible risk of glare from prolonged exposure to direct sunlight. Since glaring is an important aspect of building design that can affect human performance (ie. Physically, psychologically, and cognitively), behaviour and mood, it is particularly crucial to also consider this aspect for visual comfort in indoor environments (Ahmad et al. 2015).

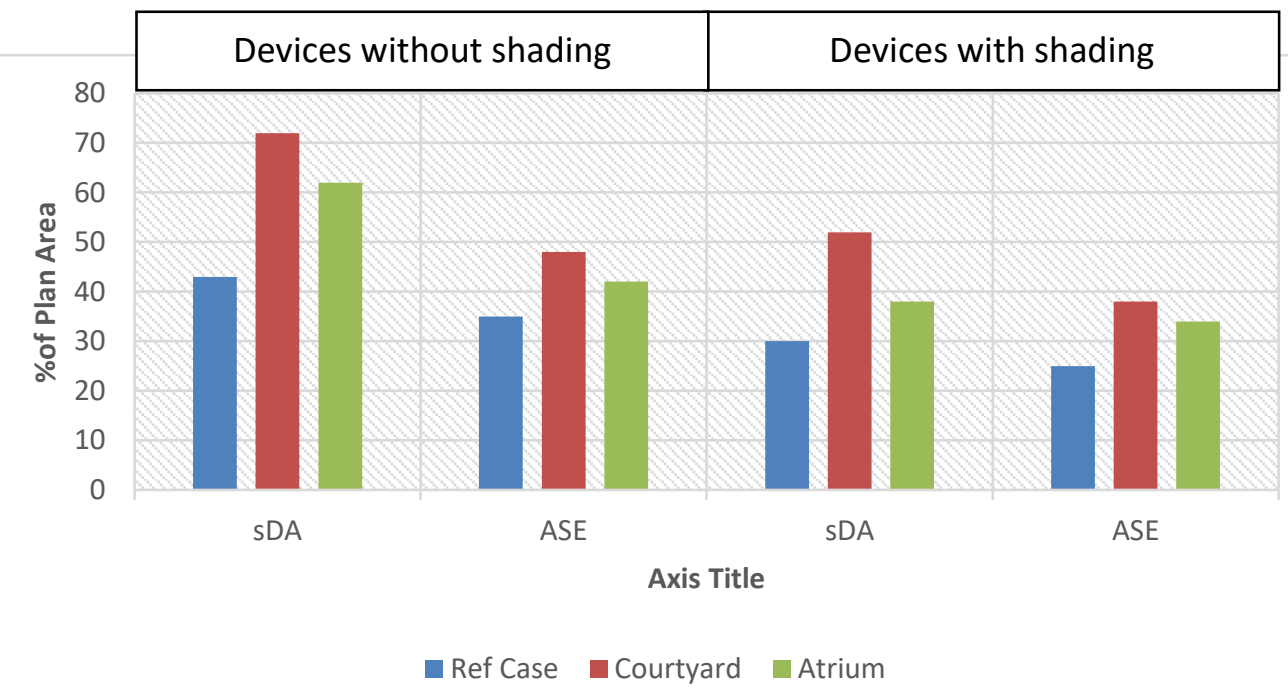

Fig. 5. Progress in the analyzed cases of SDA and ASE standards, taking into account two indicators of change and a $30 \%$ WWR rating. (Source: Author)

Figure 5 indicates the results of both methods. The $0.6 \mathrm{~m}$ horizontal overhang previously examined had been replaced by four horizontal louvres, each of which had a depth of $0.2 \mathrm{~m}$. This would improve the shade of the windows, thus reducing the risk of glare. This has decreased the area ASE1000.250 in the reference case, courtyard case and atrium cases from $41.4 \%, 57.2 \%$ and $50.8 \%$, respectively $-35.4 \%, 49.2 \%$ and $43.9 \%$. The increased shading of the windows also reduced the range of SDA300/50 to $42.7 \%, 72.2 \%$ and $62.2 \%$ respectively in referential, courtyard or atrium cases. The second measure suggested was to adjust the form of glazing to minimize direct solar penetration in space. Similarly, courtyard and atrium cases are comparison cases, this reduced the area of ASE 1000.250 to $26.9 \%, 37.3 \%$ and $33.9 \%$. Nevertheless, the range of sDA300/50\% decreased to $32.5 \%, 52.8 \%$, and $44.6 \%$ in the cases of reference. 


\subsection{Discussion}

An overview of daylight distribution is useful before the assessment of daylight availability. This is necessary to ensure indoor visual comfort (Galatioto \& Beccali, 2016). From Table 3 we can see that as WWR increases, the zone of the dark central area decreases. For the courtyard building, even when shading devices are used, daylight began to enter the building core at the lowest WWR. This is only observed with WWR at $20 \%$ and above in the atrium case. As the values of WWR increase, the dark area between the middle and the outer openings decrease. In the case of WWR $1 / 430 \%$, this dark zone is almost gone because shading devices were not used.

From Figure 3 , we can argue that the DF and SDA, particularly with low WWR values, are generally right. Figure 4 also shows that shading devices usually decrease DF levels and the central dawn strategy can increase the DF level in comparison to the reference case through atrium or courtyard openings. This applies to all WWR, but was $30 \%$ more effective because of the greater window area, particularly in courtyards' building core. DF increased dramatically from 0.81 and 0.65 to 6.7 and 5.8 in courtyard and atrium cases before shading tools were used, with WWR increasing from $10 \%$ to $30 \%$. Upon the use of shading devices, a small increase was observed. DF increased from 0.65 and from 0.55 in courtyard and atrium cases to 4.9 and 4.6 when DF increased from $10 \%$ to $30 \%$. In both cases, the working planes were $70 \%$ in the courtyard and $69 \%$ in the atrium. This is under the LEED recommended $75 \%$ limit (LEED v4 for Building and Construction, 2019).

With DF test as standard, the combined use of the SDA and ASE values argurs the availability of daylight, as well as the risk of glaring. However, between these two variables, a careful balance is needed. DesignBuilder notes that, as an appropriate range percentage of the floor area, the ASE simulation results are presented by DesignBuilder. However, this page displays the percentage of floor area earned over 1000 lux. Essentially, the SDA threshold was set at 500 lux in this study (LEED v4 for Building and Construction, 2019). Figure 4 reflects SDA and ASE performance, taking into account the different values of WWR in the case tested before and after the use of shading tools. This shows that the SDA area of not more than 1000 lux (ASE1000,250) and ASE area of more than 500/5\% is relative to the meaning of WWR. In the case of WWR, obviously, the amount of daylight is inadequate $1 / 410 \%$. By using shading tools, this was worse. The sDA area for WWR $1 / 430 \%$ was $38 \%, 65 \%$ and $47.1 \%$ respectively for the comparison, the courtyard and the atrium cases. For WWR $1430 \%$ before use of the shading equipment, these values fell to $29.9 \%, 50.1 \%$ and $37.9 \%$, respectively, when using the shading devices.

But shading devices reduced the risk of glare, while in all three cases, the ASE region decreased by $48.3 \%, 69.4 \%$ and $57.9 \%$, $57.2 \%$ and $50.8 \%$. A further increase to 30 per cent by WWR significantly increased the availability of daylight and increased luminosity risk, especially the courtyard with the highest window area. The use of shading does not seem to minimise the exposure risk. Therefore, it can be observed that a WWR of $30 \%$ is the most appropriate alternative explored in the three settings and shading.

From the findings and discussions made, the following two daylight and energy output requirements are relevant for the various examinations (1) to increase the quality of daylight and raising the chance of glare; and (2) reducing the cooling energy demand more important than the energy requirement from artificial lighting. Hence, two variables are to be considered (1) the correct application of shading devices; and (2) the right WWR interest collection.

Furthermore, we can also conclude that for daylight performance, Figure 4 indicates that rising the WWR in general results in higher levels of daylight in the cases reviewed. But, since examined shading methods have been used, just up to a WWR value of 30 per cent seems useful. This WWR value balances the availability of daily light, as measured using sDA500/30 \%, and the potential for exposure to blindness by excessively direct sunlight measured using ASE1000, 250. In this regard, several improvements were made, including changes in the type of glazing and the design of the shading device.

Also, through daylighting, the window shadowing devices are therefore the most efficient strategy with a WWR value of $30 \%$. Throughout this case, the patio and atrium had a small gain concerning daytime efficiency at the patio configuration (Figure 5). In this case, there was a minor gain. The WWR increase to 40 or $50 \%$ just boosts energy demand without increasing daylight efficiency. This shows that the impact of various interacting design parameters can be assessed through a future multi-target optimisation trial. This kind of study aims to enhance the following conflicting design objectives: reducing the demand for cooling energy, enhancing daylight availability and reducing light visual discomfort. Hence, finally, in Table 4, for the examined cases, the total energy for cooling and artificial lighting used is demonstrated.

Table 4. In the examined cases, total energy for cooling and artificial lighting is used.

\begin{tabular}{c|ccccc}
\hline \multicolumn{2}{c}{} & \multicolumn{2}{c}{ DEVICES WITHOUT SHADING } & \multicolumn{2}{c}{ DEVICES WITH SHADING } \\
\hline & & Cooling Energy & Lighting Energy & Cooling Energy & Lighting Energy \\
\hline \multirow{2}{*}{ WWR = 10 } & Ref. Case & 76.90 & 24.20 & 76.20 & 25.50 \\
& Courtyard & 79.70 & 18.00 & 78.50 & 20.20 \\
& Atrium & 81.30 & 22.40 & 80.40 & 24.50 \\
\hline \multirow{2}{*}{ WWR = 20 } & Ref. Case & 81.80 & 13.00 & 78.60 & 13.60 \\
& Courtyard & 90.10 & 9.80 & 85.20 & 12.00 \\
& Atrium & 89.40 & 12.60 & 85.70 & 13.00 \\
\hline \multirow{2}{*}{ WWR =30 } & Ref. Case & 90.10 & 11.70 & 84.60 & 11.70 \\
& Courtyard & 101.70 & 11.10 & 93.70 & 11.20 \\
& Atrium & 101.00 & 11.60 & 94.70 & 11.70 \\
\hline
\end{tabular}




\subsection{Conclusion and Recommendations}

The research showed that the WWRs was generally beneficial for artificial lighting and daylight. However, cooling energy is rising because of both solar benefits and exposed exterior walls. Shading devices could reduce this by efficiently reducing solar benefits, thereby lowering energy demand. The daylight drop is observed by use of such shading devices may be offset by the atrium or courtyard central openings. So that daylight availability, light reduction and energy charges are most effective, it is essential for the various variables interacting, namely building set-up, WWR \& window shading, to be balanced. By comparing the results of this analysis, we can conclude that both atrium and courtyards have energy savings while the atrium extra floor space matches the increased window area of the court. Effectiveness in daylight, Shading equipment with a WWR value of $30 \%$ is the most effective and safe system for the examined courthouse and atrial building construction. This combines the quality of daytime light with the elimination of glare due to prolonged direct exposure to sunlight. Changing shading device \& glazing types are some effective improvement actions in this respect. Additional study is required to build an algorithm for the optimum solution in various circumstances, taking into account the variables examined. More work is required to determine the effect of other factors, such as building shape, atrium and courtyard aspect ratios, light shelf applications and other glazing and shade tools.

\section{Acknowledgements}

We would like to thank the Centre of Studies for Architecture (COSA), UiTM for allowing the study to be conducted.

\section{Paper Contribution to Related Field of Study}

This study helps to further our understanding on the daylighting of atrium and courtyard building by comparing the performance of various Window to Wall Ratios (WWR) appropriate to Malaysia's tropical climate to help architects design more suitable buildings in a hot humid climate and ensure better comfort for occupants.

\section{References}

Ahmad, S. S., Shaari, M. F., Hashim, R., \& Kariminia, S. (2015). Conducive attributes of physical learning environment at preschool level for slow learners. ProcediaSocial and Behavioral Sciences, 201, 110-120.

Ayoub, M. (2019). 100 Years of daylighting: A chronological review of daylight prediction and calculation methods. Solar Energy, 194, 360-390. doi:https://doi.org/10.1016/j.solener.2019.10.072

Bellia, L., Fragliasso, F., \& Stefanizzi, E. (2017). Daylit offices: A comparison between measured parameters assessing light quality and users' opinions. Building and Environment, 113, 92-106. doi:https://doi.org/10.1016/j.buildenv.2016.08.014

Caicedo, D., \& Pandharipande, A. (2015). Daylight and occupancy adaptive lighting control system: An iterative optimization approach. Lighting Research and Technology, 48. doi:10.1177/1477153515587148

Du, J., \& Sharples, S. (2011). Assessing and predicting average daylight factors of adjoining spaces in atrium buildings under overcast sky. Building and Environment, 46(11), 2142-2152. doi:https://doi.org/10.1016/j.buildenv.2011.04.020

Galatioto, A., \& Beccali, M. (2016). Aspects and issues of daylighting assessment: A review study. Renewable and Sustainable Energy Reviews, $66,852-860$. doi:https://doi.org/10.1016/j.rser.2016.08.018

Gourlis, G., \& Kovacic, I. (2017). Building Information Modelling for analysis of energy efficient industrial buildings - A case study. Renewable and Sustainable Energy Reviews, 68, 953-963. doi:https://doi.org/10.1016/j.rser.2016.02.009

Hussain, S., \& Oosthuizen, P. H. (2012). Numerical investigations of buoyancy-driven natural ventilation in a simple atrium building and its effect on the thermal comfort conditions. Applied Thermal Engineering, 40, 358-372. doi:https://doi.org/10.1016/j.applthermaleng.2012.02.025

Lau, A. K. K., Salleh, E., Lim, C. H., \& Sulaiman, M. Y. (2016). Potential of shading devices and glazing configurations on cooling energy savings for high-rise office buildings in hot-humid climates: The case of Malaysia. International Journal of Sustainable Built Environment, 5(2), 387-399. doi:https://doi.org/10.1016/.ijsbe.2016.04.004

LEED v4 for BUILDING DESIGN AND CONSTRUCTION. (2019). 160.

Lim, Y.-W., Ahmad, M., \& Ossen, D. (2013). Internal Shading for Efficient Tropical Daylighting in Malaysian Contemporary High-Rise Open Plan Office. Indoor and Built Environment, 22, 932-951. doi:10.1177/1420326X12463024

Mansfield, K. (2018). Architectural lighting design: A research review over 50 years. Lighting Research \& Technology, 50(1), 80-97.

Marzouk, M., Eissa, A., \& ElSharkawy, M. (2020). Influence of light redirecting control element on daylight performance: A case of Egyptian heritage palace skylight. Journal of Building Engineering, 31, 101309. doi:https://doi.org/10.1016/j.jobe.2020.101309

Shaari, M. F., Ahmad, S. S., Ismail, I. S., \& Zaiki, Y. (2020). Preschool Physical Environment Design Quality: Addressing Malaysia's PISA Rankings. Asian Journal of Environment-Behaviour Studies, 5(16), 45-57. 
Talip , M.S., et.al., AicQoL2021, AMER International Conference on Quality of Life, Colmar Tropicale, Bukit Tinggi, Malaysia, 17-18 Mar 2021, E-BPJ, 6(16), Mar 2021 (pp.93-102)

Zain-Ahmed, A., Sopian, K., Zainol Abidin, Z., \& Othman, M. Y. H. (2002). The availability of daylight from tropical skies-a case study of Malaysia. Renewable Energy, 25(1), 21-30. doi:https://doi.org/10.1016/S0960-1481(00)00209-3 